\title{
The Northern sea route: a retrospective, strategic solutions and prospects of development
}

\author{
Anatoly Arkhipov ${ }^{1, *}$, Evgeny Grigoriev ${ }^{1}$, and Mikhail Sinitsyn ${ }^{1}$ \\ ${ }^{1}$ Siberian State University of Water Transport, Shchetinkina, 33, 630099, Novosibirsk, Russia
}

\begin{abstract}
The article considers the history of the Northern sea route formation and the current state of this transit artery, which makes it possible to determine the potential, existing problems and prospects for using the considered communication. The importance of the Arctic zone of the Russian Federation as a strategic region rich in minerals is noted. The main export and transit orientation of the Arctic communications was revealed. Attention is paid to the development of international cooperation. A review of cargo flows is given and an analysis of the state of cargo transportation in the SMP is carried out. Alternative schemes of cargo transportation from region to region are proposed, which allows to significantly reduce the cost of transport services - this will further reduce the cost of transported products for the end user. It is proposed to organize intra-basin transportation through or through the operation of all types of transport that can participate in the «SMP-regions» system. The selection criteria for each participant will be the cost of transportation. The key positions in this system are occupied by river and sea transport, since there are no other types of transport. In connection with the active development of the SMP, the system proposed by the authors will be actively developed as it coincides with the key positions of the strategy for the development of the economy and transport of the Russian Federation.
\end{abstract}

\section{Introduction}

The strategic development of the state should be based on the optimal and balanced spatial and economic development of its territories. It is determined not only by the location of production and productive forces, but also by the level of development of the transport industry, which accumulates the potential of individual modes of transport in order to align their capabilities with the level and conditions of development of international flows of goods and services.

The purpose of this study is to develop a system of cargo delivery between regions of the Russian Federation via the Northern sea route.

\footnotetext{
*Corresponding author: archi-197@mail.ru
} 


\section{Method of research}

The research conducted by the authors is based on dialectical methods of cognition and system-structural analysis that allow evaluating the dialectics of economic and technological, General and private, regional and sectoral. The work uses General scientific methods of theoretical and empirical knowledge: analogy, generalization and detail, analysis and synthesis, system approach, monographic description, transition from abstract to concrete.

\section{Research result}

Studies have shown that the developed system will allow you to revise the existing schemes of cargo delivery. Transportation of goods from one region of the Russian Federation to another via the SMP will ensure the development of networks of all types of transport, which will increase the reliability and quality of transport services provided. Thanks to the work of transport and logistics centers, it will be possible to reduce the existing basic tariffs, which will significantly reduce social tensions in the regions. Under favorable environmental conditions, there will be an increase in quantitative and qualitative indicators of the transport process. The role of the Northern regions of water transport basins will increase, which will lead to the development of these regions due to additional tax charges to the budget.

\section{The Northern sea route as a key factor in the development of the Russian Arctic}

One of the priority tasks of socio-economic development of the Russian Federation in the medium term is the development of mineral deposits in the regions of the Far North and the water area of the Arctic basin shelves. The active use of the Northern sea route is determined today, first of all, by the volume of export of hydrocarbons through it and its transit potential as an international transport corridor, the advantages of which have already been evaluated by China, Japan, and the Republic of Korea. [1,2]

The prospects for the development of the Northern sea route are complicated by the natural-climatic, hydrographic and navigational conditions of the Arctic. It should be noted that in the conditions of remoteness and inaccessibility of the territory, the economic inexpediency of increasing the volume of traffic by road and air transport, the emphasis in the formation of transport flows is transferred to the development of inland water transport. However, the insufficient development of the port-pier economy and the short navigation period currently create serious obstacles to the intensive involvement of inland water transport in the integrated multimodal transport system in the short term. [3-9]

Assessing the potential of the Northern sea route as a domestic integrative element of the global transport space, it is necessary to note the following.

The Northern sea route (Sevmorput, Northern sea corridor) is intended to provide the shortest transport path between the European part of Russia and the Far East. The length of the Northern sea route from the Kara Gate in the North-West to the Bay of Providence in the South-East is about $5600 \mathrm{~km}$, which allows connecting the seaports of St. Petersburg and Vladivostok by the shortest waterway (about $14000 \mathrm{~km}$ ). For comparison, the route through the Suez canal involves overcoming more than 23,000 km. [10,11] The Northern sea route passes through the Barents and Kara seas, the Laptev sea, the East Siberian, Chukchi and Bering seas and is divided into two sectors. The Western sector of the Arctic 
from Murmansk to Dudinka is served by rosatomflot icebreakers. The Eastern sector from Dudinka to Chukotka is served by icebreakers of the far Eastern shipping company.

\section{Retrospective and discursive aspect of the development of the Northern sea route}

Attempts to develop the North-Eastern passage (as the Northern sea route was called before the beginning of the XX century) were made from the middle of the XVI century. Not only representatives of the indigenous peoples of the North (first of all, Pomors), but also the British were active. English navigators Hugh Willoughby and Richard Chancellor in 1553 began searching for a Northern route to India and China through the Arctic ocean. One of the three ships of the expedition, equipped with «a Company of merchants and entrepreneurs to discover countries, lands, Islands, States and possessions unknown and hitherto not visited by sea», managed to land in the white sea in the Bay of St. Nicholas (near this place, 350 years later, the city of Severodvinsk was founded). The 1556 shipwreck off the coast of Norway that killed Richard Chancellor's expedition essentially delayed attempts to open the North-East passage for 200 years.

M. V. Lomonosov, in his works «a Brief description of various voyages across the Northern seas and an indication of the possible passage of the Siberian ocean to East India» (1762) and «an Appendix On Northern navigation to the East along the Siberian ocean» (1764), presented his calculations for developing a theoretical justification for the possibility of sailing across the pole to the countries of the East. In fact, the development of the Russian Arctic began in the middle of the XVIII century.

At the end of the XIX - beginning of the XX century, such outstanding Russian scientists and military specialists as D. I. Mendeleev and S. O. Makarov joined the problem of finding the route of the Northern sea route. The result of this collaboration was the development of the high-latitude icebreaker Yermak, launched in 1898 and commissioned in 1899 .

In 1878, the Swedish Navigator and Arctic Explorer Erik Nordenskiold covered almost the entire route for the first time in one navigation. He on the steamer «VEGA» carried out a through (with wintering on the way off the coast of Chukotka) navigation of the NorthEastern passage. 15 years later, Norwegian polar Explorer Fritjef Nansen on the schooner «Viking», using the constant drift of ice, overcame Cape Chelyuskin. The polar explorers who returned from their expeditions were welcomed as national heroes in their homeland, and they were surrounded by an aura of admiration and recognition in the world press.

The development of the Northern sea route is inextricably linked with the development of the Arctic. In 1900-1902, the first Russian polar expedition was conducted, organized by the St. Petersburg Academy of Sciences. On the yacht Zarya, under the guidance of Russian geologist and Arctic Explorer Eduard toll, the expedition described part of the Western coast of the Taimyr Peninsula, the Nordenskiold archipelago, and one of the lips of Kotelny island.

In 1907, the Main Hydrographic Department initiated the organization of a large-scale expedition to explore the Arctic ocean. For this purpose, two icebreaking steamers «Taimyr» and «Vaigach» were built, which in April 1910 arrived at their base in Vladivostok, and in September-October 1910 made the first expedition voyage for hydrographic research of the Bering Strait.

Even the events of 1917 and the Civil war did not stop the work of the Arctic ocean Expedition. In 1920, a «Separate Ob-Yenisei hydrographic unit» was formed, one of the tasks of which was to transport food from Siberia to the European part of Russia.

In December 1932, the GLAVSEVMORPUT (the Main Directorate of the Northern sea route) was organized by a decree of the government of the country, and in March 1933, its 
Hydrographic Department was established. They were assigned the task of laying and ensuring navigation of the Northern sea route, and equipping it with modern means of navigation equipment.

The beginning of the great Patriotic war promoted more intensive use of the Northern sea route, turning it into the main transport highway of the Soviet North. During the period from 1941 to 1945, GLAVSEVMORPUT vessels transported more than 3 million tons of military and national economic cargo. Shipping was provided by a system of sea convoys.

In the early 1950s, the active construction of diesel-electric icebreakers increased the navigation period in the Western Arctic from 1.5 to 6 months. Since the mid-1970s, thanks to the formation of the nuclear icebreaker fleet, year-round navigation on the Northern sea route has been provided.

The strategic importance of the Northern sea route was in the transport and logistics support of cargo delivery to the Northern regions of the USSR (Russian Federation) («Northern delivery»), and transportation in the opposite direction of natural resources extracted in the Arctic.

The volume of traffic on the Northern sea route (including transit cargo) is shown in figure 1 .

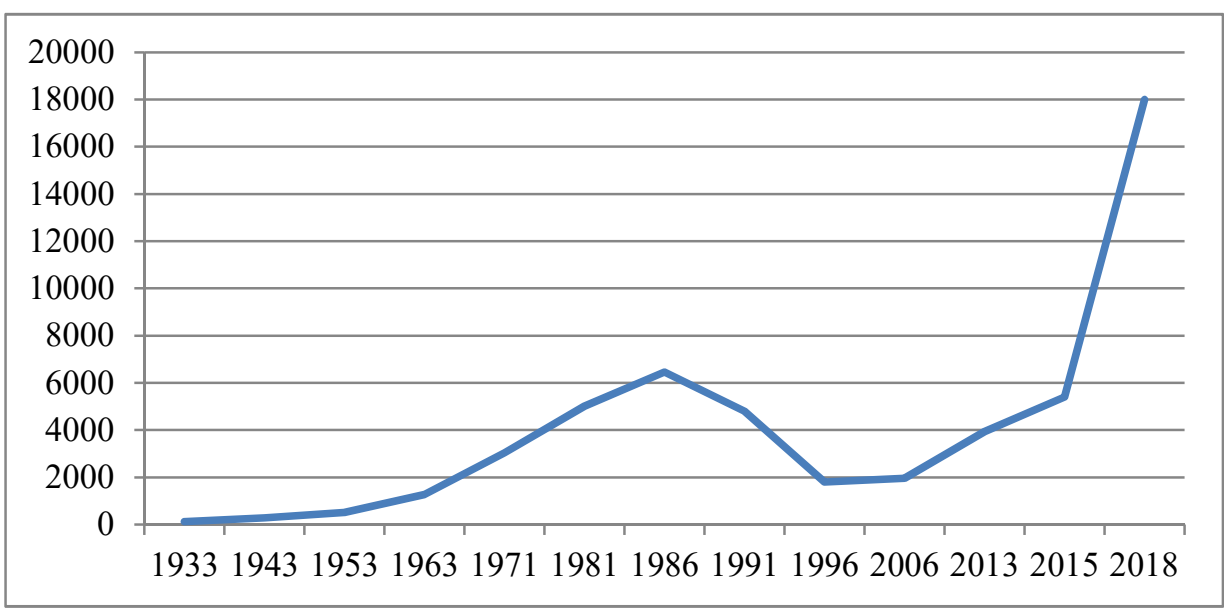

Fig. 1. Volumes of cargo transportation on the Northern sea route from 1933 to 2018, thousand tons.

It should be noted that significant traffic volumes were maintained even during the great Patriotic war. They fell somewhat during the initial period of the war. But already in 1945 they amounted to more than 500 thousand tons, and by the 1960 s they had overcome the value of 1 million tons. The Peak volume of traffic on the Northern sea route fell in 1987 6579 thousand tons, but since 1988 they have been slightly reduced. In 1988, 6295 thousand tons were transported, in 1989 - 5823 thousand tons, in $1991-4804$ thousand tons.

In the mid-1990s, there was a rapid decline in traffic. By 1996, they had decreased by almost 3 times and amounted to 1,800 thousand tons, and in the Western sector of the Northern sea route, they decreased by more than 30 times.

\section{Trends and prospects for the development of cargo flows along the Northern sea route}

Significant growth in traffic volumes began in 2006 after the implementation of major projects for the extraction of natural resources in the Arctic zone of the Russian Federation. 
This is due to the active development of the Novoportovsk oil and gas Condensate and Varandey oil fields. Since December 2013, oil production has started from the Prirazlomnaya offshore ice-resistant stationary platform, which is a unique domestic project for the production of hydrocarbons on the Arctic shelf. In 2016, the volume of traffic on the Northern sea route increased by $36 \%$ compared to 2015 and amounted to 7.26 million tons.

Since 2015, active development of coal production in the Taimyr coal basin has been started, with projected reserves of 185 billion tons. In October 2019, an intergovernmental strategic agreement was signed on the supply of coking coal from the Taimyr coal field to India.

The tendency to use the potential of the fleet more effectively is noteworthy, since the number of ships with cargo has not increased significantly during this period. The number of ballast crossings has decreased, and the number of «double» trips has increased, when the ship is carrying cargo in both directions. The volume of export and import cargo transportation is growing, and China and the Republic of Korea are the most interested foreign partners. A slight increase in traffic volumes is observed between Russian ports located in different basins («Bolshoykabotazh»). [12]

At the beginning of 2020, four nuclear-powered icebreakers («Yamal», «50 years of Victory», «Taimyr», and «Vaigach») and the world's only nuclear-powered lighter ship, Sevmorput, are operating.

In 2016, a pilot flight was carried out on the Northern sea route of a Chinese vessel. This confirms the significant interest of the PRC in the development of the Northern sea route, and attempts to integrate it into the global transport and logistics project «Maritime silk road of the XXI century», forming the route «ports of North-East Asia - Bering Strait Northern sea route-ports of Europe». [13] The results of the Arctic navigation of the last decade objectively show that in the current climate, the navigation of cargo ships along the Northern sea route to the ports of South-East Asia reduces the travel time from 10 to 22 days in comparison with the navigation through the Suez canal. This provides significant competitive advantages for shipping companies that choose the Northern option of transportation. Indeed, the tariff for icebreaking vessels on the Northern sea route is comparable to the tariff for passage through the channel, even taking into account the risk of ice damage to the vessel. The cost of an ice pilot (about 10 thousand dollars per voyage) make up $0.4-1 \%$ of shipowners expenses, depending on the type of cargo and the volume of transportation.

The Northern sea route attracts the attention of shippers and cargo carriers all over the world. Japan intends to send about $40 \%$ of its cargo to Europe via the Indian ocean and the Suez canal in the near future. In addition, China plans to actively use transit along the Northern sea route. From 2014 to 2017, it was China that delivered the most cargo - more than 1 million tons. by 2025 , China plans to transfer up to $15 \%$ of its total external cargo traffic to the Northern sea route. At the same time, the Chinese leadership declares its intention to actively develop the «Maritime silk road of the XXI century», which in the very near future will be the main flow of goods from China to Europe. [14]

Optimization of the resource component of the Northern importation is an equally urgent problem. Northern delivery is a set of annual state measures to provide the territories of the Far North with basic vital goods on the eve of the winter season. First of all, we are talking about food and oil products.

In the pre-perestroika period, the parameters of the Northern delivery were determined by the state plan of the USSR, and its annual volume was about 4 million tons. In the 1990 s, the volume of Northern imports decreased significantly. The introduction of tax incentives for the subjects participating in the Northern importation significantly improved the situation in providing the population of the region, as evidenced by the volume of water transport in 2007 (29.4 million tons) and in 2008 (27.9 million tons). 
The cancellation of benefits contributed to a sharp decline in traffic volumes. Thus, in 2009 , only 19.6 million tons were transported. One of the main reasons is the unwillingness of the participants of the Northern delivery to invest financial resources in the organization of transportation at that time. Indeed, it was necessary to pay for fuel and fuel during the pre-navigation period, and funds from the population and state subsidies could only be received after the delivery was completed.

Attempts to coordinate the activities of the Russian regions and the formation of intraregional funds for Northern delivery helped to correct the situation in 2011. The volume of traffic amounted to 24.8 million tons. However, over the period from 2012 to 2015, the volume of Northern imports gradually decreased, amounting to 20.4 million tons in 2015 . At present, there is an annual increase in the volume of Northern imports (Fig. 2).

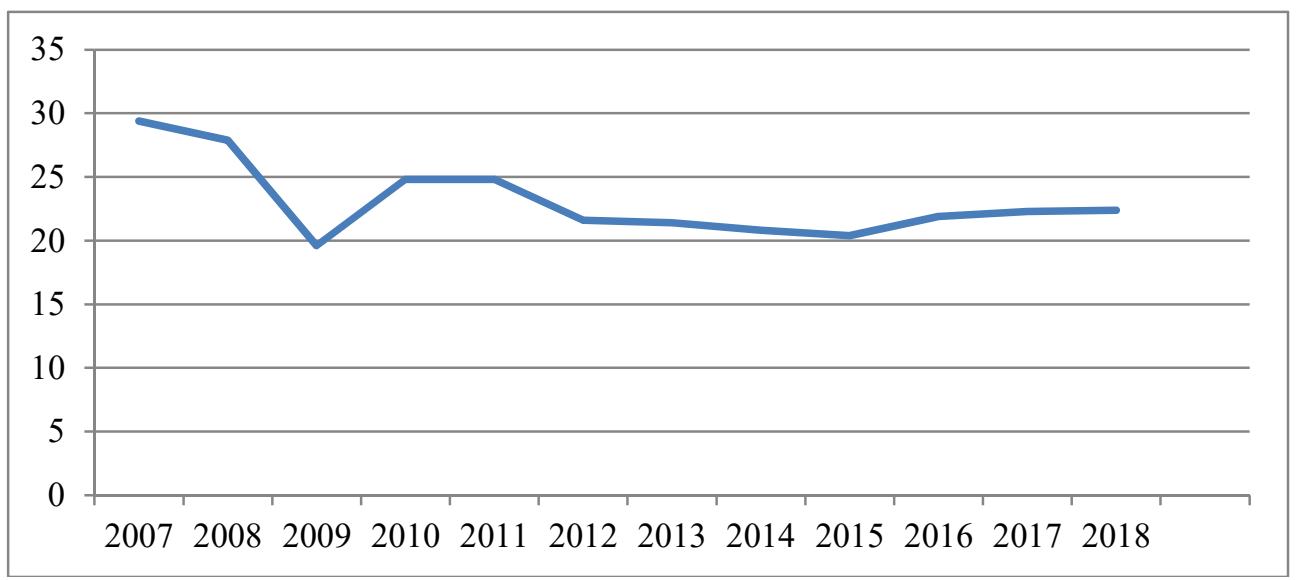

Fig. 2. The volume of Northern delivery in the years 2007-2018, millions of tons.

\section{Strategic and tactical solutions to enhance the use of the potential of the Northern sea route: methodological approaches and effectiveness}

It is important to analyze the volume of transportation in the territorial and sectoral sections, taking into account the dynamics of the population in the supplied regions of the Far North. To cope with this difficult problem, the organization of a kind of «Northern pool» will help, whose tasks will include assessing the resource potential of individual commodity-supplying regions, and forming intra-regional funds for Northern delivery. This will contribute to optimizing the choice of variant of delivery of the North with the possibility of early delivery during the navigation period in the Siberian rivers (including small), air travel (including for Canada airships), winter roads on riverbeds etc.

It should be noted that the southern regions of Western Siberia (especially Altai Krai and Novosibirsk oblast and Omsk, Tomsk, and Kemerovo oblasts), the southern regions of Eastern Siberia (primarily, Krasnoyarsk Krai and Irkutsk oblast and the Republic of Khakassia) is able to provide the relevant Northern territory the main part of the vital goods.

The priority of the South-North vertical is determined by the presence of natural water transport arteries (Ob, Irtysh, Yenisei, Lena) that can significantly increase the volume of traffic by the most cost-effective river transport.

The waterways of the Northern territories of the Russian Federation are part of the transport system for the delivery of goods to the Arctic regions. Their participation is key 
here, since most of the cargo will be transported by river transport due to the lack of alternatives. River transport plays a pioneering role here, and it will not change in the future until 2030. [15]

River transport is a link between the Northern sea route and other participants in the transport process. The extensive river network of the Siberian regions allows and will provide access to the most important points of industrial and economic development of the regions, where there is no availability for other types of transport.

The use of river transport for bulk cargo transportation is much cheaper than other modes of transport and often does not incur any additional capital investment in infrastructure, since natural waterways are used, even if they are necessary, they are 6-10 times less than other modes of transport.

The potential of the Northern sea route provides an opportunity for transportation between water transport basins of the Russian Federation. At the moment, these are small shipments, but in the future they are expected to grow significantly. So, in the Northern part of the Yenisei basin, there are no all types of transport except for river and sea transport. Therefore, in the future, it is possible to deliver energy resources from the Ob-Irtysh basin. The experience of such transportations can be applied in other basins.

An alternative to the Northern sea route is the southern sea route. The distance from the regional ports on the SMP is 5770 nautical miles, and on the southern one - 12840 nautical miles.

Figure 3 shows a diagram of the movement of cargo flows along the Northern sea route.

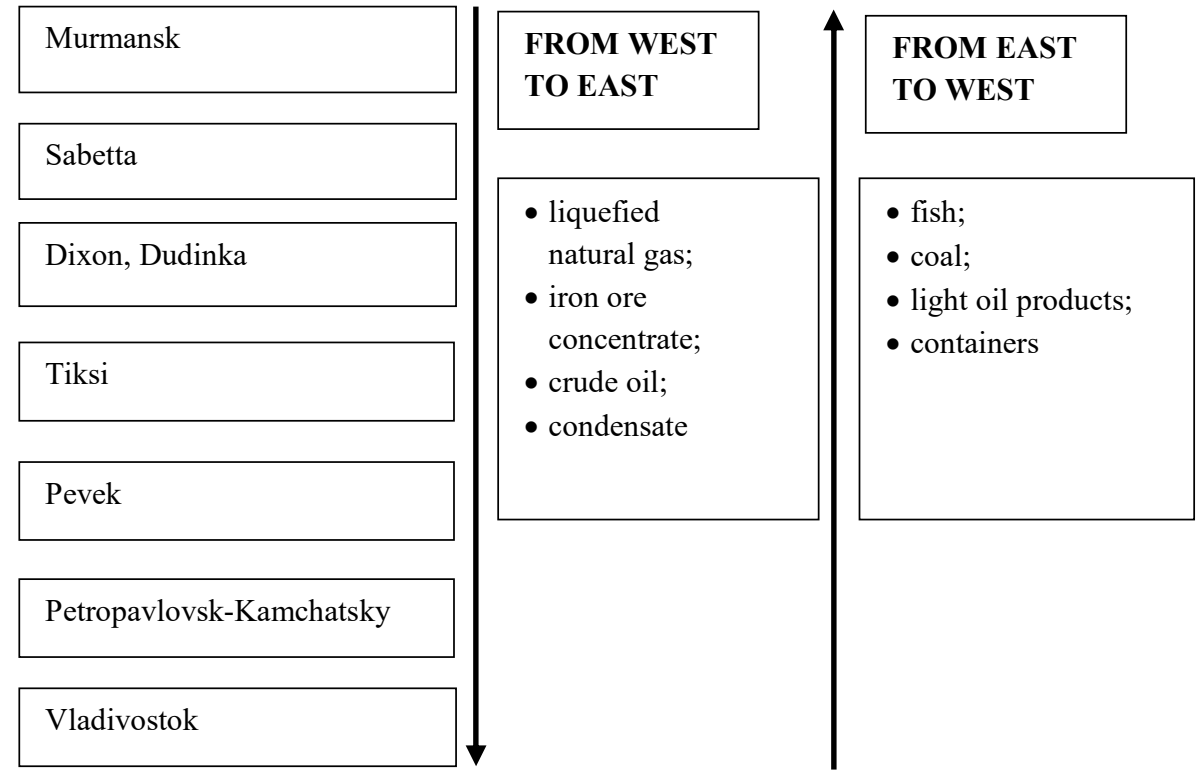

Fig. 3. Diagram of the movement of cargo flows along the Northern sea route. 


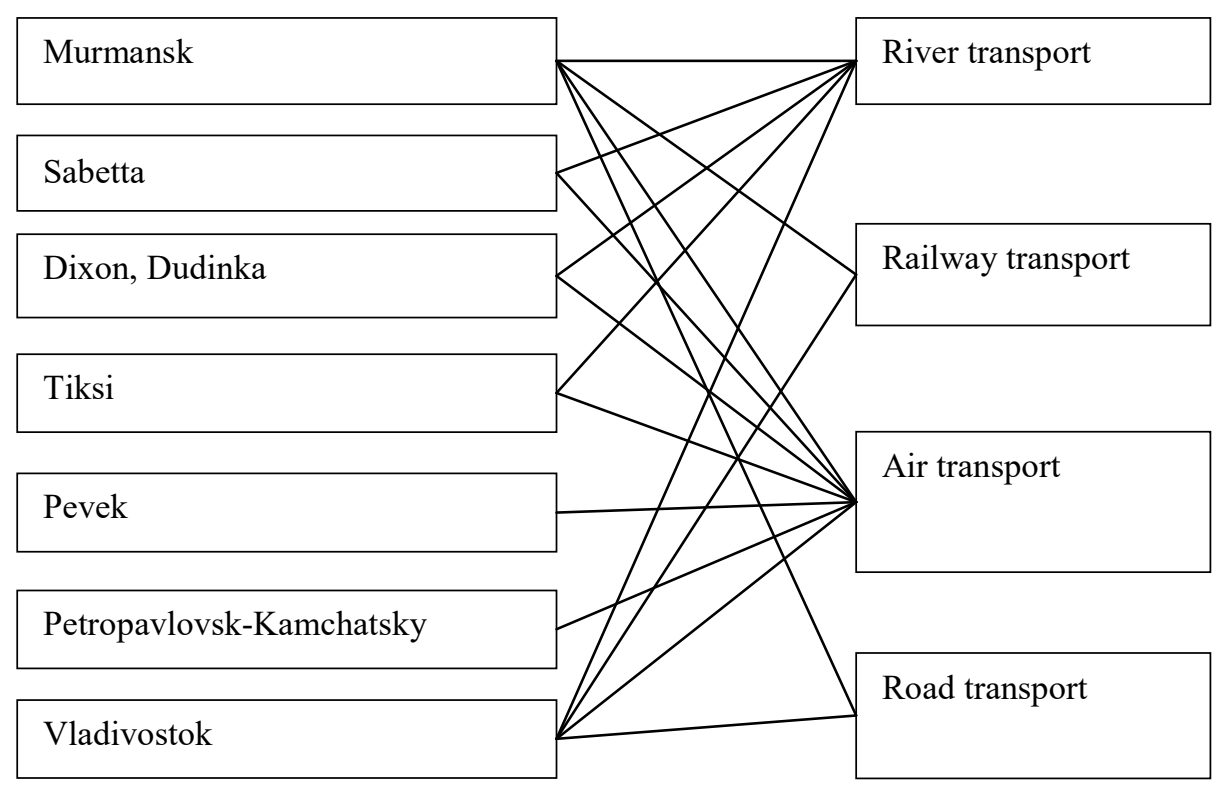

Fig. 4. Possible delivery routes to points included in the Northern sea route system.

Analyzing figure 4, we can conclude that the main mode of transport for the delivery of energy resources and other types of cargo to the points included in the SMP system is river transport.

The cost of cargo delivery will consist of the total cost of transportation and reloading.

$$
C_{d}=\sum G \cdot S_{l i}+\sum G \cdot L_{i} \cdot S_{c i}
$$

$G$ - cargo traffic according to the scheme under consideration, thousand tons;

$S_{l i}$ - cost of loading in the $i$-th reloading link of the logistics chain, RUB / ton;

$G \cdot L_{i}-$ cargo turnover in the area under consideration, million tkm;

$S_{c i}$ - cost of cargo transportation by the $i$-th type of transport, RUB / t. km

The rational delivery option will be selected when all costs associated with the movement of cargo are taken into account, in our case they will be based on the formula:

$$
\sum C=C_{d}+C_{m}+C_{o}+C_{i},
$$

$C_{d}$ - delivery costs, RUB.;

$C_{m}$ - inventory maintenance costs, RUB.;

$C_{o}$ - organizational costs, RUB.;

$C_{i}$ - the cost of insurance, RUB.

In order to assess the effectiveness of the cargo delivery system to the points of the Northern sea route, the choice of an efficiency indicator is of primary importance. A performance indicator is a measure of how well a real result matches what is needed.

The main requirement for selecting an efficiency indicator is its compliance with the purpose of functioning of the system, which is displayed by the desired result.

In General, the effectiveness criterion is considered to be a rule that allows comparing management strategies that are characterized by different degrees of achievement of the goal, and making a directed choice of strategies from a set of acceptable ones. The efficiency criterion can be made on the basis of a certain concept of the decision on the effectiveness of the system.

There are three main concepts: 
- suitability;

- optimalities;

- adaptations.

\section{Discussion of results}

The system being created will allow to meet the needs of the regions in due measure, increase the efficiency of cargo delivery, reduce the cost of cargo delivery, and increase the reliability of the transport process. The role of the regulator in this system will be performed by the state, since a number of transport operations in this direction are important for the state and are included in the program of the regional development strategy.

\section{References}

1. S.-W. Lee, J.-M. Song, The Asian Journal of Shipping and Logistics 30(3), 415-430 (2014)

2. C. Pierre, F. Olivier, Transportation Research Part A: Policy and Practice 78, 337-346 (2015)

3. C. Farias Almeida, J. Gomes Gularte, Y. Yamashita, Procedia - Social and Behavioral Sciences 162, 90-100 (2014)

4. P. Phani Kumar, Manoranjan Parida, Mansha Swami, Procedia - Social and Behavioral Sciences 104, 795-804 (2013)

5. M. Kotachi, G. Rabadi, M.F. Obeid, Procedia Computer Science 20, 229-234 (2013)

6. A. Idri, M. Oukarfi, A. Boulmakoul, K. Zeitouni, A. Masri, Procedia Computer Science 109, 692-697 (2017)

7. L. Zhang, H. Yang, D. Wu, D. Wang, Transportation Research Part C: Emerging Technologies 49, 73-86 (2014)

8. Mihai-Cosmin Niculescu, Marius Minea, Transportation Research Procedia 14, 14531462 (2016)

9. A. Idri, M. Oukarfi, A. Boulmakoul, K. Zeitouni, A. Masri, Transportation Research Procedia 27, 294-300 (2017)

10. Y. Zhang, Q. Meng, S. Hui Ng, Journal of Transport Geography 57, 241-249 (2016)

11. Y. Zhang, Q. Meng, L. Zhang, Marine Policy 73, 53-60 (2016)

12. D. Theocharis, V. Sanchez Rodrigues, S. Pettit, J. Haider, Transportation Research Part E: Logistics and Transportation Review 129, 111-135 (2019)

13. O. Kherbash, M. Liviu Mocan, Procedia Economics and Finance 27, $42-47$ (2015)

14. A.-S. Milaković, B. Gunnarsson, S. Balmasov, S. Hong, S. Ehlers, Marine Policy 94, 53-60 (2018)

15. D.-Y. Lin, Y.-T. Chang, Transportation Research Part E: Logistics and Transportation Review 110, 47-70 (2018) 